\title{
ANALISIS RISIKO BENCANA ERUPSI GUNUNGAPI SUNDORO DI KECAMATAN NGADIREJO KABUPATEN TEMANGGUNG
}

\author{
Oleh: \\ Akhmad Ganang Hasib', Dyah Respati Suryo Sumunar² \\ ${ }^{1}$ Mahasiswa Jurusan Pendidikan Geografi FIS UNY \\ ${ }^{2}$ Staf Pengajar Jurusan Pendidikan Geografi FIS UNY \\ Gananghasib86@ymail.com
}

\begin{abstract}
Abstrak
Penelitian ini bertujuan mengetahui: (1) pengaruh faktor bahaya, kerentanan, dan kapasitas, (2) tingkat dan sebaran risiko bencana erupsi Gunungapi Sundoro. Penelitian ini merupakan penelitian survey deskriptif dengan pendekatan kuantitatif. Populasi meliputi seluruh wilayah Kecamatan Ngadirejo dengan pengambilan sampel secara purposive berdasarkan Peta KRB Gunungapi Sundoro. Pengumpulan data dengan wawancara dan observasi untuk memperoleh data kapasitas; dokumentasi dan interpretasi untuk memperoleh data kerentanan dan bahaya. Analisis data dengan overlay, scoring, dan deskriptif. Hasil penelitian menunjukkan (1) Faktor bahaya, kerentanan, dan kapasitas memiliki pengaruh yang bervariasi terhadap terjadinya bencana. (2) Tingkat dan sebaran risiko bencana erupsi dibagi menjadi sedang, rendah, dan sangat rendah. Tingkat risiko sedang mendominasi sebagian wilayah Desa Katekan dan Giripurno. Tingkat risiko rendah mendominasi sebagian besar wilayah Katekan, Tegalrejo, dan Giripurno. Tingkat risiko sangat rendah mendominasi sebagian Purbosari, Tegalrejo, dan Banjarsari. Tingkat risiko sangat rendah di wilayah Medari, Campursari, Manggong, Gondangwinangun, Karanggedong, Kataan, Ngadirejo, Gandu Wetan, Munggangsari, Gejagan, Pringapus, dan Mangunsari.
\end{abstract}

Kata kunci: Erupsi Gunungapi Sundoro, Risiko Bencana, Kecamatan Ngadirejo

\begin{abstract}
This research aims at investigating: (1) the influence of hazard, vulnerability, and coping capacity factor, (2) the level and distribution of eruption disaster risk of Sundoro Volcano. This research is a descriptive-survey research employing quantitative approach. The population include all terrains in Ngadirejo Subdistrict. The samples were taken using purposive sampling technique based on KRB map. The interviews and observations were intended to obtain data of capacity; while the documentations and interpretations were directed to obtain data of vulnerability and hazard. Data analysis was performed using overlay, scoring, and descriptive. The results are: (1) hazard, vulnerability, and capacity have different influences on disaster. (2) the level and distribution of volcanic disaster risk is divided into moderate, low, and very low. Moderate level is dominated in most area of Katekan, Tegalrejo, and Giipurno. Low risk is dominated in most area of Purbosari, Tegalrejo, and Banjarsari. Very low level is dominated in Medari, Campursari, Manggong, Gondangwinangun, Karanggedong, Kataan, Ngadirejo, Gandu Wetan, Munggangsari, Gejagan, Pringapus, and Mangunsari.
\end{abstract}

Keywords: Sundoro Volcano Eruption, Disaster Risk, Ngadirejo Subdistrict 


\section{PENDAHULUAN}

Pulau Jawa merupakan salah satu bagian dari ring of fire di Indonesia. Di Pulau Jawa terdapat rangkaian gunungapi yang memanjang dari barat ke timur. Gunung Sundoro (sebagian masyarakat lokal menyebut Gunung Sindoro), dan Gunung Sumbing merupakan dua gunungapi yang terletak pada bagian tengah Provinsi Jawa Tengah tepatnya pada perbatasan antara Kabupaten Wonosobo, Kabupaten Temanggung dan Kabupaten Magelang. Kecamatan Ngadirejo di Kabupaten Temanggung ialah salahsatu wilayah yang terletak di kaki kedua gunungapi ini.

Kondisi Topografi Kecamatan Ngadirejo sangat dipengaruhi oleh adanya Gunung Sundoro. Hal ini menjadikan Kecamatan Ngadirejo memiliki relief pegunungan dan lembah-lembah. Gunung Sundoro memberikan banyak manfaat pada penduduk yang tinggal di bawahnya, termasuk penduduk Kecamatan Ngadirejo. Mereka adalah warga masyarakat yang rentan karena tinggal terlalu dekat dengan sumber ancaman. Wilayah seperti ini pada umumnya mempunyai daya tarik dalam rupa tanah yang subur untuk bercocok tanam, mata air dan pemandangan yang menarik, sehingga masyarakat senang tinggal dan beraktivitas di wilayah tersebut. Wilayah Kecamatan Ngadirejo tergolong memiliki lahan yang subur, sehingga banyak penduduk yang bekerja pada sektor pertanian. Selain itu, wilayah Kecamatan Ngadirejo juga memiliki potensi pariwisata yang cukup potensial untuk dikembangkan yaitu Komplek Situs Liyangan yang ditemukan kembali tahun 2008. Komplek Situs Liyangan masih mengalami proses ekskavasi oleh para ahli sampai dengan penelitian ini dilaksanakan.

Gunung Sundoro merupakan gunungapi tipe A, artinya memiliki catatan aktivitas kegunungapian semenjak tahun 1600-an. Gunung Sundoro memiliki ketinggian 3.150 mdpl. Manfaat yang diperoleh dari adanya gunungapi ini sangat beragam, akan tetapi potensi bahaya yang dapat di timbulkan juga tidak kalah besar. Aktivitas kegunungapian yang ditunjukan Gunung Sundoro tidak terlalu besar apabila dibandingankan dengan gunungapi lain seperti Gunung Merapi dan Gunung Kelud dalam jangka 10 tahun terakhir. Menurut V. M. Y. Degroot (2009: 71) Gunung Sundoro agak lebih aktif dari pada Gunung Sumbing yang berada di sebelah tenggaranya.

Tercatat terakhir kali Gunung Sundoro mengalami peningkatan aktivitas pada akhir tahun 2011. Pada saat itu status Gunung Sundoro sempat naik dari aktif normal menjadi waspada. Menurut Thornbury (1969: 16) dalam ilmu geomorfologi dikenal adanya sebuah konsep yaitu hukum dan proses fisika yang sama yang berlaku saat ini, berlangsung pula sepanjang waktu geologi meskipun intensitasnya tidak selalu sama dengan intensitasnya saat ini. Hal tersebut menunjukan bahwa Gunung Sundoro dapat mengalami peningkatan aktivitas sewaktu-waktu atau bahkan terjadinya erupsi meskipun saat ini statusnya aktif normal.

Situs Liyangan yang sekarang menjadi aset berharga pariwisata di Kabupaten Temanggung khususnya Kecamatan Ngadirejo juga menjadi petunjuk aktivitas kegunungapian Gunung Sundoro pada masa lampau. Keunikan situs ini ialah sebuah 
perdusunan Mataram Kuno ditemukannya bekas-bekas rumah dan pertanian pada masa lalu. Situs Liyangan terkubur kedalam beberapa tahapan yaitu terkubur oleh aliran awan panas yang dibuktikan dengan material piroklastik pada lapisan yang terletak paling bawah. Tahap kedua ialah adanya aliran lahar yang mengubur Situs Liyangan dibuktikan dengan material batu yang tersebar tidak beraturan menurut ukurannya. Tahap terakhir ialah terkuburnya Situs Liyangan oleh endapan dari debu vulkanik dan lapili. Bukti-bukti tersebut mengindikasikan adanya sebuah peristiwa besar yang terjadi pada masa lalu di Komplek Situs Liyangan sesuai dengan teori "the present is the key to the past" yang dikemukakan oleh Thornbury (1969: 17).

Kecamatan Ngadirejo memiliki karakteristik wilayah yang berpotensi menimbulkan risiko bencana yang diakibatkan oleh erupsi gunungapi. Faktorfaktor bahaya yang berpotensi terjadi di Kecamatan Ngadirejo merupakan suatu keadaan yang tidak dapat diubah. Hal ini merupakan konsekuensi dari kondisi wilayah Kecamatan Ngadirejo baik secara geologis, geomorfologis, dan klimatis yang sangat potensial mengalami bencana alam terutama erupsi gunungapi. Dalam jangka satu dekade terakhir Gunung Sundoro tidak menampakan aktivitas kegunungapian yang signifikan. Hasil observasi awal yang dilakukan peneliti menunjukan bahwa ketiadaan aktivitas kegunungapian yang signifikan dalam jangka waktu lama menyebabkan kurangnya pengetahuan penduduk mengenai ancaman bahaya di Kecamatan Ngadirejo. Potensi terjadinya bencana di Kecamatan Ngadirejo tidak hanya dipengaruhi oleh faktor bahaya saja, akan tetapi juga faktor kerentanan dan kapasitas bencana. Potensi terjadinya bencana menyebabkan timbulnya risiko yang harus dihadapi penduduk yang hidup di Kecamatan Ngadirejo (Nurjanah dkk, 2011: 15). Penanggulangaan bencana memerlukan berbagai faktor pendukung antaralain berupa informasi mengenai risiko bencana alam. Sampai saat ini belum ada kajian secara menyeluruh terhadap sebaran tingkat risiko bencana yang ditimbulkan oleh adanya erupsi gunungapi di Kecamatan Ngadirejo.

Berdasarkan latar belakang tersebut, salah satu elemen penting dalam penanggulangan bencana adalah informasi tingkat risiko bencana. Informasi ini dapat dimanfaaatkan sebagai acuan baik pra bencana (mitigasi dan kesiapsiagaan), penanganan darurat pada saat bencana, maupun pemulihan pasca bencana (Sudibyakto, 124: 2011). Oleh karena itu, peneliti tertarik untuk mengadakan penelitian kajian tingkat risiko bencana alam di Kecamatan Ngadirejo dengan judul "Analisis Risiko Bencana Erupsi Gunungapi Sundoro di Kecamatan Ngadirejo Kabupaten Temanggung".

\section{METODE}

Penelitian ini merupkakan penelitian survei deskriptif. Hasil penelitian ini digunakan untuk mengetahui pengaruh faktor-faktor bahaya, kerentanan, dan kapasitas terhadap terjadinya bencana erupsi Gunung Sundoro dan mengetahui tingkat dan sebaran risiko bencana erupsi Gunung Sundoro di Kecamatan Ngadirejo.

Populasi dalam penelitian ini ialah seluruh desa atau kelurahan di Kecamatan Ngadirejo yang termasuk dalam Kawasan Rawan Bencana (KRB) Gunung Sundoro. Sampel dalam penelitian ini ditentukan menggunakan teknik purpossive sampling berdasarkan 
peta KRB untuk memperoleh data kapasitas bencana. Penentuan lokasi pengembilan sampel berdasarkan pada luas dan tingkat bahaya bencana erupsi di setiap desa atau kelurahan yang terancam. Data bahaya dan kerentanan merupakan data sekunder yang diperoleh menggunakan teknik interpretasi dan dokumentasi, sedangkan data kapasitas merupakan data primer yang diperoleh menggunakan teknik wawancara.

Penelitian ini menggunakan pendekatan kuantitatif dalam melakukan analisis data. Data yang terkumpul selanjutnya akan dianalisis menggunakan teknik scoring dan overlay dalam Sistem Informasi Geografis (SIG), serta analsis deskripstif untuk menunjukan sebaran tingkat risiko bencana erupsi Gunung Sundoro.

\section{HASIL DAN PEMBAHASAN}

Berdasarkan hasil analisis diketahui bahwa masing-masing faktor bahaya, kerentanan, dan kapasitas memiliki karakteristik tersendiri dalam mempengarhui terjadinya bencana erupsi Gunungapi Sundoro di Kecamatan Ngadirejo. Faktor bahaya adalah faktor yang berasal dari alam yang sifatnya tidak dapat dirubah, sedangkan faktor kerentanan dan kapasitas adalah faktor yang berasal dari penduduk setempat yang sifatnya dapat dirubah. Faktor bahaya dan kerentanan adalah faktor yang dapat meningkatkan tingkat risiko bencana, sedangkan faktor kapasitas adalah faktor yang dapat memperkecil tingkat risiko bencana. Berikut ialah pembahasan tingkat dan sebaran pada masing-masing variabel yang berpengaruh terhadap tingkat risiko bencana.

1. Tingkat dan Sebaran Bahaya pada Bencana Erupsi Gunungapi Sundoro Tingkat dan sebaran Bahaya erupsi Gunung Sundoro dibagi menjadi:

a. KRB (Kawasan Rawan Bencana) I

1) Kawasan Rawan Bencana terhadap Aliran Massa (Lahar dan Awan Panas)

Kawasan rawan bencana terbadap aliran massa berupa lahar dan kemungkinan perluasan atau penyimpangan awan panas. Lahar kemungkinan besar dapat terjadi di bagian timur dan timurlaut Gunung Sundoro melalui sungai-sungai besar yang mengalir ke arah tersebut.

2) Kawasan Rawan Bencana terhadap Lontaran Batu (Pijar)

Berdasarkan erupsi Gunung Sundoro di masa silam menunjukan bahwa Iontaran batu (Pijar) berukuran maksimum $2 \mathrm{~cm}$ dapat mencapai jarak antara 5-8 $\mathrm{km}$ dari pusat erupsi, sedangkan abu letusan dapat mencapai jarak lebih dari 8 $\mathrm{km}$.

b. KRB (Kawasan Rawan Bencana) II

1) Kawasan Rawan Bencana terhadap Aliran Massa.

Kawasan awan bencana terhadap aliran massa Gunung Sundoro di bedakan menjadi dua bagian yaitu:

a) Kawasan Rawan Bencana terhadap Aliran Piroklastik (Awan Panas)

b) Kawasan Rawan Bencana terhadap Aliran Lava

2) Kawasan Rawan Bencana terhadap Bahan Lontaran dan Hujan Abu Lebat 
Bahan lontaran adalah semua jenis bahan letusan yang di lontarkan ke semua arah pada saat terjadi letusan berupa bom vulkanik berasal dari magma dan juga pecahan batuan tua.

c. KRB (Kawasan Rawan Bencana) III

1. Kawasan Rawan Bencana terhadap Awan Panas

Berdasarkan data geologi dan sejarah kegiatan masa lampau menunjukkan bahwa produk letusan Gunung Sundoro didominasi oleh aliran piroklastik (awan panas) dan aliran lava.

Berikut ialah luas masing-masing KRB bencana erupsi Gunung Sundoro di Kecamatan Ngadirejo :

Tabel 1. Luas Wilayah Terancam per KRB di Kecamatan Ngadirejo

\begin{tabular}{|l|l|l|l|}
\hline No. & \multicolumn{1}{|c|}{ KRB } & \multicolumn{1}{|c|}{$\begin{array}{c}\text { Luas Wilayah } \\
\text { Terancam (ha) }\end{array}$} & \multicolumn{1}{|c|}{$\begin{array}{c}\text { \% Luas Wilayah } \\
\text { Terancam Total }\end{array}$} \\
\hline 1. & KRB I & 881,21 & 37,71 \\
\hline 2. & KRB II & $1.308,73$ & 56,00 \\
\hline 3. & KRB III & 146,96 & 6,29 \\
\hline \multicolumn{2}{|l|}{ Jumlah } & $2.336,90$ & 100,00 \\
\hline \multicolumn{2}{|l|}{ Rata-rata } & 778,97 & 33,33 \\
\hline
\end{tabular}

Sumber : Analisis Data Sekunder, 2014

2. Tingkat dan Sebaran Kerentanan pada Bencana Erupsi Gunung Sundoro Tingkat dan sebaran kerentanan bencana dibagi menjadi:

a. Kerentanan Sosial

Kerentanan sosial terhadap bencana erupsi Gunung Sundoro di Kecamatan Ngadirejo memiliki dua tingkat kerentanan. Tingkat kerentanan tinggi mendominasi hampir semua wilayah desa di Kecamatan Ngadirejo, kecuali Desa Pringapus dan Desa Gejagan yang memilki tingkat kerentanan sedang.

b. Kerentanan Ekonomi

Kerentanan ekonomi terhadap bencana erupsi Gunung Sundoro di Kecamatan Ngadirejo memiliki tiga tingkat kerentanan. Tingkat kerentanan tinggi mendominasi di wilayah desa yang terletak relatif lebih dekat dengan Gunung Sundoro seperti Desa Katekan, Giripurno, Tegalrejo, Purbosari, dan Banjarsari.

c. Kerentanan Fisik

Kerentanan fisik terhadap bencana erupsi Gunung Sundoro di Kecamatan Ngadirejo memiliki tiga tingkat kerentanan. Tingkat kerentanan tinggi mendominasi di wilayah Desa Katekan, Giripurno, dan Manggong.

d. Kerentanan Lingkungan 
Kerentanan lingkungan (penggunaan lahan) terhadap bencana erupsi Gunung Sundoro di Kecamatan Ngadirejo memiliki dua tingkat kerentanan. Pada setiap desa tersebar dua tingkat kerentanan lingkungan yaitu tingkat sedang dan tinggi.

e. Kerentanan Total

Kerentanan total terhadap bencana erupsi Gunung Sundoro di Kecamatan Ngadirejo memiliki empat tingkat kerentanan. Tingkat kerentanan sangat tinggi mendominasi di wilayah desa yang terletak relatif lebih dekat dengan Gunung Sundoro seperti Desa Katekan, Giripurno, Tegalrejo, Purbosari, dan Banjarsari. Faktor yang paling mempengaruhi tingkat kerentanan sangat tinggi di desa-desa tersebut ialah desa-desa tersebut memiliki tingkat kerentanan tinggi pada variabel kerantanan fisik, sosial, ekonomi, dan lingkungan.

Tingkat Kerentanan tinggi ada di Desa Dlimoyo, Medari, Campursari, dan Manggong. Gondangwinangun, Karanggedong, dan Mangunsari. Faktor yang paling mempengaruhi tingkat kerentanan tinggi di desa-desa tersebut ialah desa-desa tersebut memiliki tingkat kerentanan tinggi pada variabel kerentanan sosial dan memiliki tingkat kerentanan sedang pada variabel kerentanan ekonomi, fisik, dan lingkungan.

Tingkat kerentanan sedang ada di Desa Kataan, Ngadirejo, Gondangwinangun, Karanggedong, Gandu Wetan, dan Munggangsari. Faktor yang paling mempengaruhi tingkat kerentanan sedang di desa-desa tersebut ialah desa-desa tersebut memiliki tingkat kerentanan sedang pada variabel kerentanan fisik dan kerentanan rendah pada variabel kerentanan ekonomi.

Tingkat kerentanan rendah ada di Desa Pringapus dan Gejagan. Faktor yang paling mempengaruhi tingkat kerentanan rendah di desa-desa tersebut ialah desa-desa tersebut memiliki tingkat kerentanan rendah dan sebagian kecil sedang pada semua variabel kerentanan baik fisik, sosial, ekonomi, dan lingkungan.

Berikut ialah luas masing-masing tingkat kerentanan bencana erupsi Gunung Sundoro di Kecamatan Ngadirejo.

Tabel 2. Luas Wilayah pada Setiap Tingkat Kerentanan di Kecamatan Ngadirejo

\begin{tabular}{|l|l|l|l|}
\hline No. & \multicolumn{1}{|c|}{$\begin{array}{c}\text { Tingkat } \\
\text { Kerentanan }\end{array}$} & \multicolumn{1}{|c|}{$\begin{array}{c}\text { Luas Wilayah } \\
\text { Terancam (ha) }\end{array}$} & \multicolumn{1}{|c|}{$\begin{array}{r}\text { \% Luas Wilayah } \\
\text { Terancam Total }\end{array}$} \\
\hline 1. & Sangat Tinggi & $1,775,19$ & 53,30 \\
\hline 2. & Tinggi & 636,84 & 19,12 \\
\hline 3. & Sesdang & 660,52 & 19,83 \\
\hline 4. & Rendah & 258,12 & 7,75 \\
\hline \multicolumn{2}{|l}{ Jumlah } & $3.330,66$ & 100,00 \\
\hline
\end{tabular}




\begin{tabular}{|l|l|l|}
\hline Rata-rata & 832,67 & 25,00 \\
\hline
\end{tabular}

Sumber : Analisis Data Sekunder, 2014

3. Tingkat dan Sebaran Kapasitas pada Bencana Erupsi Gunung Sundoro

Kapasitas total terhadap bencana erupsi Gunung Sundoro di Kecamatan Ngadirejo memiliki dua tingkat kapasitas. Tingkat kapasitas rendah mendominasi di wilayah desa yang terletak relatif lebih dekat dengan Gunung Sundoro seperti Desa Katekan dan Giripurno. Faktor yang paling mempengaruhi tingkat kapasitas rendah di kedua desa tersebut ialah ketiadaan lokasi pengungsian. Kedua desa tersebut merupakan desa yang paling dekat jaraknya dengan puncak Gunung Sundoro, sehingga apabila terjadi erupsi warga kedua desa akan mengungsi ke desa-desa yang terletak di bagian timur desa tersebut.

Tingkat kapasitas sedang ada di Desa Tegalrejo, Purbosari, Banjarsari, Dlimoyo, Medari, Campursari, Manggong Karanggedong, Kataan, Ngadirejo, Gondangwinangun, Karanggedong, Gandu Wetan, Munggangsari dan Mangunsari. Faktor yang paling mempegaruhi tingkat kapasitas sedang di desadesa tersebut ialah keberadaan lokasi pengungsian. Hal ini dikarenakan desadesa tersebut terletak lebih jauh dari puncak Gunung Sundoro, sehingga apabila terjadi erupsi desa-desa tersebut lebih layak untuk dijadikan lokasi pengunungsian daripada Desa Katekan dan Giripurno.

Berikut ialah luas masing-masing tingkat kapasitas bencana erupsi Gunung Sundoro di Kecamatan Ngadirejo.

Tabel 3. Luas Wilayah Terancam pada Setiap Tingkat Kapasitas di Kecamatan Ngadirejo

\begin{tabular}{|l|l|l|l|}
\hline No. & \multicolumn{1}{|c|}{ Tingkat Kapasitas } & \multicolumn{1}{|c|}{$\begin{array}{c}\text { Luas Wilayah } \\
\text { Terancam (ha) }\end{array}$} & \multicolumn{1}{|c|}{$\begin{array}{r}\text { \% Luas Wilayah } \\
\text { Terancam Total }\end{array}$} \\
\hline 1. & Rendah & 992,42 & 29,80 \\
\hline 2. & Sedang & $2.338,24$ & 70,20 \\
\hline \multicolumn{2}{|l|}{ Jumlah } & $3.330,66$ & 100,00 \\
\hline \multicolumn{2}{|l|}{ Rata-rata } & $1.665,33$ & 50,00 \\
\hline
\end{tabular}

Sumber : Analisis Data Primer, 2014

Berdasarkan tingkat dan sebaran bahaya, kerentanan, dan kapasitas bencana tingkat risiko dibagai menjadi tiga yaitu sedang, rendah, dan sangat rendah. Tingkat risiko sedang mendominasi sebagian wilayah Desa Katekan dan Giripurno. Faktor yang paling mempengaruhi ialah sebagian wilayah yang memiliki tingkat risiko sedang di kedua desa tersebut merupakan wilayah KRB III yang memiliki ancaman bahaya paling tinggi apabila terjadi erupsi Gunungapi Sundoro. Faktor lain yang mempengaruhi ialah 
dominasi tingkat kerentanan sangat tinggi dan tingkat kapasitas yang rendah di wilayah ini.

Tingkat risiko rendah mendominasi wilayah besar wilayah Desa Katekan, Tegalrejo dan Giripurno. Wilayah dengan tingkat risiko rendah ini memiliki tingkat kerentanan sangat tinggi dan kapasitas rendah, akan tetapi sebagian besar wilayah dengan tingkat risiko tinggi berada di wilayah KRB II yang memiliki ancaman bahaya lebih rendah dibandingkan KRB III.

Tingkat risiko sangat rendah mendominasi sebagian Desa Purbosari, Tegalrejo, dan Banjarsari. Tingkat risiko sangat rendah juga berada ada di wilayah Desa Medari, Campursari, Manggong, Gondangwinangun, Karanggedong, Desa Kataan, Ngadirejo, Karanggedong, Gandu Wetan, Munggangsari, Gejagan, Medari, Pringapus, dan Mangunsari. Faktor yang paling mempengaruhi ialah sebagian besar wilayah dengan tingkat risiko sangat rendah berada di wilayah KRB I. Faktor lain yang juga mempengaruhi ialah tingkat kerentanan yang didominasi dari tingkat kerentanan sangat rendah sampai rendah. Selain itu, tingkat kapasitas di wilayah dengan tingkat risiko sangat rendah ini memiliki tingkatan rendah.

Berikut ialah luas masing-masing tingkat risiko bencana erupsi Gunung Sundoro di Kecamatan Ngadirejo.

Tabel 3. Luas Wilayah Terancam pada Setiap Tingkat Risiko di Kecamatan

Ngadirejo

\begin{tabular}{|l|l|c|c|}
\hline No. & \multicolumn{1}{|c|}{ Tingkat Risiko } & $\begin{array}{c}\text { Luas Wilayah } \\
\text { Terancam (ha) }\end{array}$ & $\begin{array}{c}\text { \% Luas Wilayah } \\
\text { Terancam Total }\end{array}$ \\
\hline 1. & Sedang & 146,96 & 7,00 \\
\hline 2. & Rendah & 1080,52 & 51,50 \\
\hline 3. & Sangat Rendah & 870,50 & 41,49 \\
\hline & Jumlah & $2.097,98$ & 100,00 \\
\hline & Rata-rata & 699,33 & 33,33 \\
\hline
\end{tabular}

Sumber : Analisis Data Primer dan Sekunder, 2014

\section{SIMPULAN}

Berdasarkan pemaparan diatas dapat diambil beberapa kesimpulan antara lain: (1) Masing-masing faktor bahaya, kerentanan, dan kapasitas memiliki karakteristik tersendiri dalam mempengarhui terjadinya bencana erupsi Gunungapi Sundoro di Kecamatan Ngadirejo. (2) Tingkat risiko bencana erupsi Gunung Sundoro di Kecamatan Ngadirejo memiliki beberapa tingkatan risiko. Tingkat risiko dibagi menjadi tiga tingkat yaitu sedang, rendah, dan sangat rendah. Semakin tinggi tingkat risiko bencana maka potensi kerugian akibat terjadinya bencana erupsi Gunung Sundoro semakin besar baik berupa kematian, luka, sakit, jiwa, terancam, hilangnya rasa aman, mengungsi, kerusakan atau kehilangan harta, dan gangguan kegiatan masyarakat. Potensi kerugian ini akan semakin menurun jika tingkat risiko menurun. Tingkat risiko bencana akibat erupsi Gunungapi di Kecamatan Ngadirejo tersebar diseluruh wilayah. Tingkat risiko sedang dengan luas 146,96 ha 
mendominasi sebagian wilayah Desa Katekan dan Giripurno. Tingkat risiko rendah dengan luas 1080,52 ha mendominasi sebagian besar wilayah Katekan, Tegalrejo dan Giripurno. Tingkat risiko sangat rendah dengan luas 870,50 ha mendominasi sebagian Desa Purbosari, Tegalrejo, dan Banjarsari. Tingkat risiko sangat rendah juga berada ada di wilayah Desa Medari, Campursari, Manggong, Gondangwinangun, Karanggedong, Kataan, Ngadirejo, Gandu Wetan, Munggangsari, Gejagan, Medari, Pringapus, dan Mangunsari.

\section{UCAPAN TERIMA KASIH}

Tulisan ini merupakan bagian dari penelitian tugas akhir skripsi yang berjudul Analisis Risiko Bencana Erupsi Gunungapi Sundoro di Kecamatan Ngadirejo Kabupaten Temanggung. Dalam kesempatan ini penulis mengucapkan terima kasih yang sebesarbesarnya kepada berbagai pihak yang telah membantu dalam proses penelitian, khususnya kepada pembimbing tugas akhir.

\section{DAFTAR PUSTAKA}

Degroot, V.M.Y. (2009). Candi Space and Landscape: A Study on the Distribution, Orientation and Spatial Organization of Central Javanese Temple Remains. Disertasi. Universiteit Leiden.

Nurjanah, dkk (2011). Menejemen Bencana. Bandung: Alfabeta.

Sudibyakto. (2011). Manajemen Bencana di Indonesia ke Mana?. Yogyakarta: Gadjah Mada University Press.

Thornbury, W. D. (1969). Principles of Geomorphology. New York: John Wiley. 